\title{
Gradual withdrawal of remifentanil delays initial post-operative analgesic demand after thyroid surgery; double-blinded, randomized controlled trial
}

Sarah Saxena ${ }^{1,2^{*}}$ (D) Kimberly Gonsette ${ }^{1}$, Willy Terram ${ }^{1}$, Isabelle Huybrechts', Daniel A. Nahrwold ${ }^{2,3}$, Matteo Cappello ${ }^{4}$, Luc Barvais ${ }^{1}$ and Edgard Engelman ${ }^{1}$

\begin{abstract}
Background: Mismanagement of remifentanil leads to severe side effects such as opioid-induced tolerance and hyperalgesia. Recently studies revealed an alternative withdrawal method to limit these side effects. A gradual withdrawal of remifentanil seems to be associated with less pain. The hypothesis of this double-blinded, randomized controlled trial was that a gradual withdrawal of remifentanil would be associated with less immediate post-operative pain compared to after an abrupt discontinuation of remifentanil in patients who underwent thyroid surgery.

Methods: This double-blinded, randomized controlled trial was conducted in a tertiary level hospital in Brussels (Belgium) from April until August 2017. 34 patients undergoing thyroid surgery were randomized and 29 patients completed the study. After randomization, patients undergoing thyroid surgery were allocated to two groups: one with an abrupt discontinuation of remifentanil after surgery and one with a gradual withdrawal of remifentanil after surgery. The primary outcome was the initial post-operative demand of analgesic medication.

Results: Gradual withdrawal of remifentanil was associated with a delayed initial post-operative demand of analgesic medication $(P=0.006)$. The first morphine bolus was given after $76.3+/-89.0 \mathrm{~min}$ in the group with a gradual withdrawal of remifentanil versus after $9.0+/-13.5 \mathrm{~min}$ in the group with an abrupt discontinuation of remifentanil. However, overall morphine consumption, numeric rating scale scores, Ramsay Sedation Scale scores, and quality of recovery scores (QoR-40) were similar in both groups $(P>0.05)$.

Conclusion: Though overall morphine consumption, numeric rating scale scores, Ramsay Sedation Scale scores, and quality of recovery scores (QoR-40) are not altered, a gradual withdrawal of remifentanil after thyroid surgery is safe and associated with a delayed initial post-operative demand of analgesic drugs. The withdrawal process does, however, require vigilance and training.
\end{abstract}

Trial registration: Clinicaltrials.gov NCT03110653 (PI: Luc Barvais; date of registration: 03/31/2017).

\footnotetext{
*Correspondence: sarah.saxena@ulb.ac.be

'Department of Anesthesia and Perioperative Care, CUB Erasme University Hospital, Université Libre de Bruxelles, 808, Route de Lennik, 1070 Brussels, Belgium

${ }^{2}$ Department of Anesthesia and Perioperative Care, Zuckerberg San Francisco

General Hospital \& Trauma Center, University of California, San Francisco,

USA

Full list of author information is available at the end of the article
}

(c) The Author(s). 2019 Open Access This article is distributed under the terms of the Creative Commons Attribution 4.0 International License (http://creativecommons.org/licenses/by/4.0/), which permits unrestricted use, distribution, and reproduction in any medium, provided you give appropriate credit to the original author(s) and the source, provide a link to the Creative Commons license, and indicate if changes were made. The Creative Commons Public Domain Dedication waiver (http://creativecommons.org/publicdomain/zero/1.0/) applies to the data made available in this article, unless otherwise stated. 


\section{Background}

Over the last decade, remifentanil has been subjected to bad press $[1,2]$. Initially, this drug was hailed for its benefits which included being an ultra short-acting phenylpiperidine opioid analgesic with high lipid solubility, having a rapid onset of action, and being rapidly metabolized by non-specific blood and tissue esterases. For these reasons, many anesthesiologists became accustomed to using remifentanil. It can be given in high doses, is easily titratable, and leads to predictable, rapid recoveries.

However, the mismanagement of remifentanil can lead to a wide range of side effects including opioid-induced tolerance and hyperalgesia. Additionally, due to its rapid elimination, a bridge to post-operative analgesia is a necessity when administering this drug.

Opioid tolerance is defined as an increase in the dose required to maintain analgesia in patients receiving opioids for pain relief in the clinical setting. Opioid-induced hyperalgesia is a state of nociceptive sensitization and is defined as increased pain from a stimulus that normally provokes pain [3]. While clear definitions are accepted, the underlying mechanisms behind these concepts are still widely misunderstood and remain under investigation.

Recently, studies have been published about an alternative withdrawal method of remifentanil. Albrecht et al. demonstrated that immediate discontinuation of remifentanil after digestive surgery is associated with increased postoperative pain levels [4].

A gradual withdrawal of remifentanil may be associated with less pain in a rodent population [5]. Several research groups have evaluated this hypothesis in healthy human volunteers and have seemingly confirmed the theory that a gradual withdrawal of remifentanil is associated with less pain $[6,7]$.

Our group wanted to put this theory into practice within the perioperative period. The hypothesis of this double-blinded, randomized controlled trial was that a gradual withdrawal of remifentanil would be associated with less immediate post-operative pain compared to after an abrupt discontinuation of remifentanil in patients undergoing thyroid surgery.

\section{Methods}

\section{Ethics}

This study was designed adhering to the Declaration of Helsinki and the CONSORT checklist, and was approved by the internal review board (03/30/2017; P2017/074; Comité Ethique, Erasme hospital, Brussels; Chairman: Jean-Marie Boeymans). The trial was registered on clinicaltrials.gov (NCT03110653; PI: Luc Barvais; date of registration: 03/31/2017). Written informed consent was obtained from each patient participating in the study.

Inclusion criteria were the following: male or female patients aged 18-65 undergoing thyroid surgery at the
Erasme hospital, Brussels, ASA physical status of I-III, and a knowledge of French, English, or Dutch.

Exclusion criteria were the following: pregnancy, hypo or hyperthyroidism, gastro-duodenal ulcer, allergy or contraindications to one of the study drugs, renal insufficiency, liver insufficiency, neuropsychiatric disturbance, BMI > 30, history of drug and alcohol abuse, and preoperative analgesic drug use.

The main objective of this study was to evaluate immediate post-operative pain levels in patients who underwent two types of remifentanil withdrawal methods. The timing of the first demand of post-operative analgesic was compared in both groups. In parallel, post-operative morphine consumption was also compared between both groups, as well as numeric rating scale (NRS) values at rest and after a small head flexion. In this way, pain was evaluated after $0,15,30,45,60,75,90,105,120 \mathrm{~min}$, and $4 \mathrm{~h}$ after admission to the post-anesthesia care unit (PACU), as well as $24 \mathrm{~h}$ post-operatively. A quality of recovery (QoR-40) questionnaire was given to each patient preand post-operatively to evaluate patient satisfaction [8]. In the PACU, sedation was assessed in both groups via the Ramsay Sedation Scale [9].

Patients were randomized to one or the other group using a computer-generated randomization list (QuickCalcs program-GraphPad Software Inc., La Jolla, USA). For premedication, all patients received alprazolam (0.5 mg P.O.) one hour pre-operatively. Multi-parameter monitoring was used according to our institution's protocol (ECG, pulse oximetry, non-invasive blood pressure every three minutes, Bispectral Index (BIS), and neuromuscular blockade monitoring utilizing the trainof-four ratio). In the case of blood pressure dropping $20 \%$ or more from initial baseline measurement, a bolus of intravenous ephedrine was administered.

Anesthesia was induced intravenously in both groups with remifentanil TCI (Minto model; $5 \mathrm{ng} \mathrm{ml}^{-1}$; approximately $0.15 \mathrm{mcg} \mathrm{kg}^{-1} \mathrm{~min}^{-1}$ ) and propofol TCI (Schnider model; starting at $3 \mathrm{mcg} \mathrm{ml}^{-1}$; adjusted to BIS levels between 45 and 55). Rocuronium $\left(0.6 \mathrm{mg} \mathrm{kg}^{-1}\right)$ was then administered to facilitate tracheal intubation. After tracheal intubation, but pre-incision, remifentanil levels were lowered to $2 \mathrm{ng} \mathrm{ml}^{-1}$ (approximately $0.065 \mathrm{mcg} \mathrm{kg}^{-1} \mathrm{~min}^{-1}$ ). Just before incision, remifentanil levels were increased to $5 \mathrm{ng} \mathrm{ml}^{-1}$, and acetaminophen $(1000 \mathrm{mg})$, diclofenac $\left(1 \mathrm{mg} \mathrm{kg}^{-1}\right)$ and morphine $\left(0.15 \mathrm{mg} \mathrm{kg}^{-1}\right)$ were administered as co-analgesics. Dexamethasone $(10 \mathrm{mg})$ was administered to both groups. By the end of the surgery, ondansetron ( $4 \mathrm{mg}$ ) was given to all patients. Upon skin closure, remifentanil levels were progressively lowered to $3.5 \mathrm{ng} \mathrm{ml}^{-1}$ (approximately $0.13 \mathrm{mcg} \mathrm{kg}^{-1} \mathrm{~min}^{-1}$ ). By the end of the surgery, propofol TCI was discontinued and remifentanil was kept at $2 \mathrm{ng} \mathrm{ml}^{-1}$. Tracheal extubation was accomplished after adequate spontaneous ventilation 
was ensured, as well as the patient's responsiveness to verbal commands.

The patients were then transferred to the PACU with the remifentanil TCI infusion pump running at $2 \mathrm{ng} \mathrm{ml}^{-1}$. Back check valves and continuous saline infusion were used in the IV line in order to avoid backflow, dead space syndrome, or unintentional bolus.

According to pre-operative randomization, the remifentanil infusion syringe was then switched in the PACU to a new syringe, which was prepared by a colleague (WT) who was independent of the study. This post-operative syringe was either remifentanil diluted to $20 \mathrm{mcg} / \mathrm{ml}$ or $\mathrm{NaCl} 0.9 \%$. PACU nurses and the primary anesthesiologist did not know whether their patients had received a newly prepared remifentanil or $\mathrm{NaCl} 0.9 \%$ syringe.

A gradual decrease of this infusion was then started in the PACU according to the following protocol: a reduction in infusion rate of $30 \%$ every $15 \min (2->1.4->1$ - > $0.7->0.5$ $->0.35->0.25->0 \mathrm{ng} \mathrm{ml}^{-1}$ ). This gradual decrease was achieved in two hours.

While in the PACU, intravenous morphine ( $2 \mathrm{mg}$ every five minutes) was administered if a patient's pain was more than $3 / 10$ on the NRS. All patients were monitored and under immediate medical surveillance, and therefore no limit was imposed on total morphine consumption. Additionally, acetaminophen $(1000 \mathrm{mg}$ every $6 \mathrm{~h})$ and diclofenac $\left(1 \mathrm{mg} \mathrm{kg}^{-1}\right.$ every $\left.12 \mathrm{~h}\right)$ were administered to all patients. Patients stayed a minimum of four hours in the PACU and were discharged from the PACU once they were comfortable (e.g. NRS $<3 / 10$, no postoperative nausea and vomiting, Ramsay scores of 2-3, no hematoma at the surgical site).

The total quantities of each drug used, as well as the different timings (induction, incision, end of surgery, and extubation times), were recorded. The primary anesthesiologist collected data pre-operatively and postoperatively (the first $24 \mathrm{~h}$ post-operation).

\section{Statistical analysis}

As the primary outcome of the study was to compare the first post-operative demand of analgesic drugs, we considered a difference of $35 \mathrm{~min}$ or more to be of clinical relevance. With a two-sided alpha level of 0.05 and power of $90 \%$ (standard deviation (SD) of $27 \mathrm{~min}$ ), the study needed to be conducted on 26 patients with each group consisting of 13 patients.

Statistix 9.0 (Analytical Software, Tallahassee, USA) was used for statistical analyses. The results were presented as mean \pm standard deviation. $P$ values $<0.05$ were considered to be statistically significant. The Mann-Whitney $\mathrm{U}$ test was used for the analysis of the first demand of analgesic drug data, morphine consumption data, QoR-40 data, and NRS score data at $24 \mathrm{~h}$. NRS values and Ramsay scale scores in the PACU were analyzed using a two-way ANOVA for repeated measures.

\section{Results}

Thirty-four patients were randomized from April to August 2017 (Fig. 1). Three patients were excluded from analysis due to missing data. Additionally, the protocol was not adhered to in two patients. Therefore, 29 patients were analyzed with 15 in the remifentanil group and 14 in the control group.

Patient characteristics are described in Table 1. Age, weight, BMI, gender, and ASA scores were collected for both groups pre-operatively. Our primary outcome measure was the timing of the initial demand of postoperative analgesic drug, and our data analysis revealed a statistically significant difference between the two groups $(P=0.006)$. The first morphine bolus was given $76.3 \pm 89.0 \mathrm{~min}$ post-operatively in the remifentanil group and $9.0 \pm 13.5 \mathrm{~min}$ in the control group (Table 2).

A statistically significant difference in morphine consumption was not observed while patients were in the PACU $(P=0.251)$. In addition, there was no difference in overall (intra- and post-operative) morphine consumption $(P=0.325$; Table 2). Examination of NRS values in the PACU showed no statistically significant between-group differences both at rest $(P=0.358)$ and during head flexion $(P=0.418$; Table 3 ; Fig. 2$)$. Review of these same NRS values $24 \mathrm{~h}$ post-operatively on the ward did not demonstrate any statistically significant betweengroup differences $(p=0.113$; Table 2$)$. Furthermore, analysis of the QoR-40 scores exhibited no differences between the groups $(P=0.513$; Table 2$)$. Ramsay scores, indicating the patient's sedation level, were not different between the groups $(P=0.337$; Table 4$)$.

\section{Discussion}

This double-blinded, randomized controlled trial showed that a gradual decrease of remifentanil levels is associated with a delayed initial demand of post-operative analgesic drug. This corresponds with what others have already described in healthy volunteers $[6,7]$.

Remifentanil-induced hyperalgesia remains a misunderstood concept, with multiple theories attempting to find its cause. One interesting cellular model for pain amplification and hyperalgesia after opioid withdrawal is referred to as the long-term potentiation (LTP) of synaptic strength in nociceptive pathways. Opioid withdrawal LTP has been described as the following: "A brief application of remifentanil in vivo leads to acute depression of synaptic strength in C-fibers. Upon withdrawal, synaptic strength not only quickly returns to normal, but becomes potentiated for prolonged periods of time" [10]. A study on spinal dorsal horns from rats showed that 


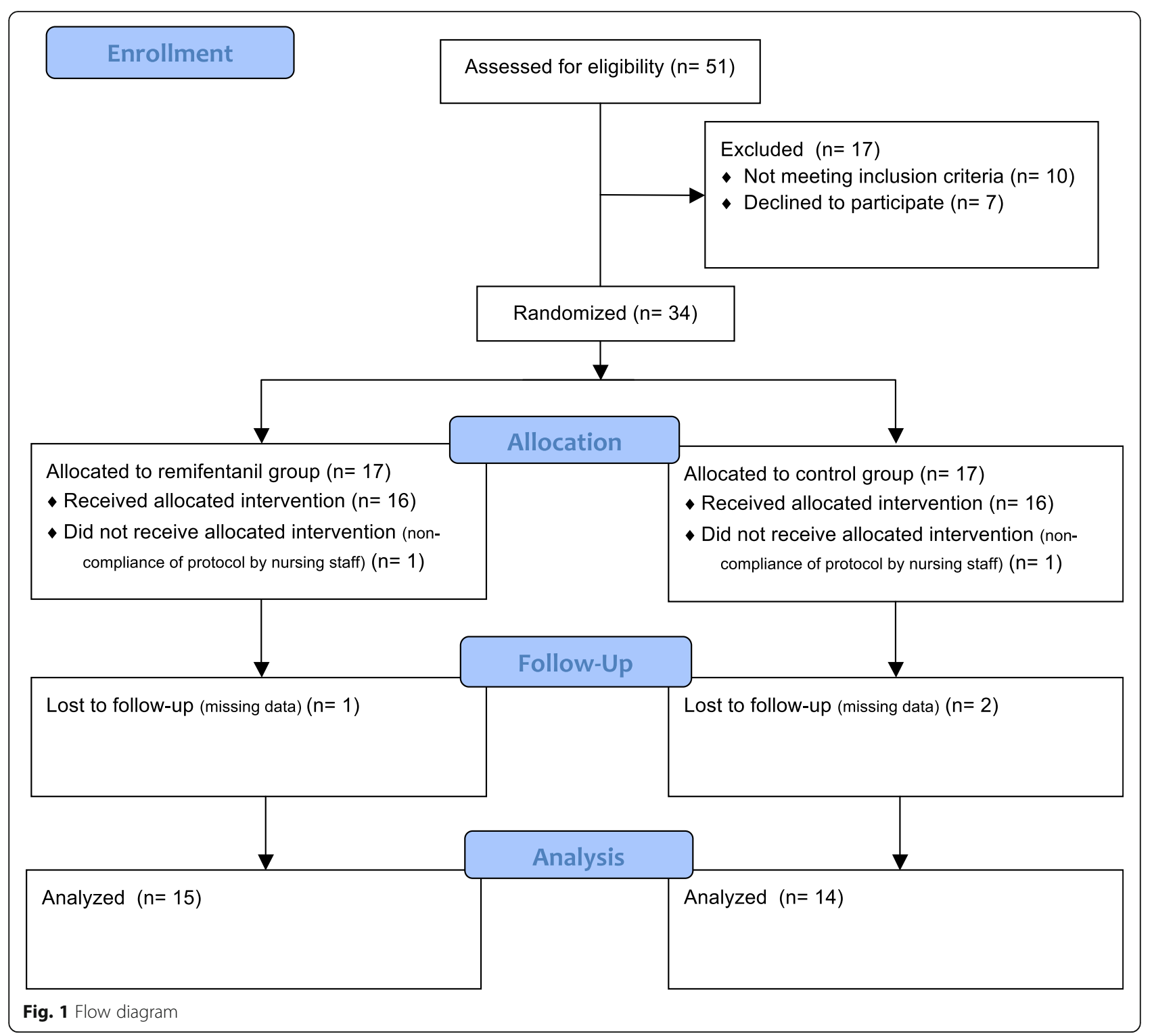

withdrawal LTP may be prevented by tapering of the remifentanil infusion instead of abrupt withdrawal [5]. This LTP could indeed explain why a gradual withdrawal of remifentanil was associated with a delayed initial post-operative analgesic demand.

Table 1 Demographic data

\begin{tabular}{llll}
\hline & Remifentanil group & Control group & $P$ value \\
\hline Age (years) & $42.0 \pm 10.3$ & $44.6 \pm 12.2$ & 0.50 \\
Weight $(\mathrm{kg})$ & $72.5 \pm 13.3$ & $78.1 \pm 20.5$ & 0.56 \\
BMI $\left(\mathrm{kg} / \mathrm{m}^{2}\right)$ & $26.5 \pm 4.7$ & $27.2 \pm 5.8$ & 0.91 \\
Gender (F/M) & $14 / 1$ & $12 / 2$ & 0.60 \\
ASA score (1/2) & $2 / 13$ & $0 / 14$ & 0.48 \\
\hline
\end{tabular}

Data as Mean \pm SD or number of patients - Analysis by Mann-Whitney $\mathrm{U}$ test or Fisher exact test
Another theory explaining remifentanil-induced hyperalgesia is the activation of the N-methyl-D-aspartate (NMDA) receptor, which counteracts its analgesic effects. Indeed, blocking NMDA receptors can prevent this development by decreasing the activation of pronociceptive systems that are triggered by opioids [11].

In our study, remifentanil was administered in conjunction with propofol. Propofol, by inhibiting the NMDA subtype of the glutamate receptor, may have a preventative effect on remifentanil-induced hyperalgesia $[1,12]$.

The administration mode of remifentanil was based on the Minto model, which is relatively standard for most European countries. A TCI mode of remifentanil seems to be associated with less hyperalgesia [13].

The analgesia protocol of this trial was designed to prevent post-operative pain as much as possible [3]. A 
Table 2 Initial demand of post-operative analgesic, morphine consumption, QoR-40 scores, NRS values (24 h)

\begin{tabular}{|c|c|c|c|}
\hline & Remifentanil group & Control group & $\begin{array}{l}P \text { value for difference } \\
\text { between groups }\end{array}$ \\
\hline $\begin{array}{l}\text { Time to administration of the first iv morphine } \\
\text { bolus (min) }\end{array}$ & $76.3 \pm 89.0(45.0)$ & $9.0 \pm 13.5(3.5)$ & 0.006 \\
\hline $\begin{array}{l}\text { Supplementary postoperative morphine during } \\
\text { the first } 4 \text { post-operative hours (mg) }\end{array}$ & $6.4 \pm 5.1(6.0)$ & $8.3 \pm 3.9(8.0)$ & 0.251 \\
\hline $\begin{array}{l}\text { Supplementary morphine, including the } \\
\text { administration at the beginning of surgery, } \\
\text { during the first } 4 \text { post-operative hours (mg) }\end{array}$ & $16.6 \pm 4.9(17.0)$ & $18.0 \pm 4.2(18.5)$ & 0.325 \\
\hline $\begin{array}{l}\text { Numeric rating scale score for pain at rest } \\
24 \mathrm{~h} \text { after surgery }\end{array}$ & $1.85 \pm 1.46(2.5)$ & $0.91 \pm 1.37(0.0)$ & 0.113 \\
\hline QoR-40 score & $173.4 \pm 16.3(176.0)$ & $179.0 \pm 10.8(178.5)$ & 0.513 \\
\hline
\end{tabular}

Data as Mean \pm SD (median) - Analysis by Mann-Whitney U test

multimodal analgesia regimen (consisting of NSAIDS, acetaminophen, and timely administered morphine) is standard practice in our institution and was therefore applied to this study. This allowed us to keep remifentanil levels relatively low (at maximum $5 \mathrm{ng} \mathrm{ml}^{-1}$ or approximately $0.15 \mathrm{mcg} \mathrm{kg}^{-1} \mathrm{ml}^{-1}$ ).

In this study, remifentanil was gradually withdrawn in the PACU over the course of two hours, though at present, no consensus exists regarding the exact withdrawal method of remifentanil.

As mentioned, mismanagement of remifentanil administration leads to severe side effects. This study was conducted with extreme caution and required training of the nursing and anesthesia staff in order to avoid accidental boluses, especially during transport from the operating room to the PACU. In this way, episodes of respiratory depression and apnea were nonexistent (SP02 remained $>95 \%$ at all times). Sedation levels were the same in both groups, and all patients underwent anesthesia and the subsequent $24 \mathrm{~h}$ post-operative period uneventfully.

\section{Limitations}

A limitation of our study was that hyperalgesia was not properly assessed through pain threshold tests at the surgical site. Pain was evaluated through the NRS, total morphine consumption, and initial post-operative demand of an analgesic.

Even though this initial demand of an analgesic was delayed through a gradual withdrawal of remifentanil, overall morphine consumption was quite low and equal in both groups $(16.6 \pm 4.9 \mathrm{mg}$ in the remifentanil group versus $18.0 \pm 4.2 \mathrm{mg}$ in the control group). This could be explained by the fact that a well-timed multimodal analgesia plan was applied to both groups. Additionally, our study may not have been powered to show a difference in morphine consumption.

Though the difference in immediate post-operative NRS values between both groups was not statistically significant, some interesting observations can be made. While both groups benefitted from the same perioperative multimodal analgesia strategy, raw NRS values

Table 3 Numeric Rating Scale (NRS) Values for Pain

\begin{tabular}{|c|c|c|c|c|c|c|c|c|c|c|}
\hline & $\begin{array}{l}\text { PACU } \\
\text { arrival }\end{array}$ & $\begin{array}{l}\mathrm{PACU}+15 \\
\min \end{array}$ & $\begin{array}{l}\mathrm{PACU}+30 \\
\min \end{array}$ & $\begin{array}{l}\mathrm{PACU}+45 \\
\min \end{array}$ & $\begin{array}{l}\mathrm{PACU}+60 \\
\min \end{array}$ & $\begin{array}{l}\text { PACU + } 75 \\
\min \end{array}$ & $\begin{array}{l}\text { PACU + } 90 \\
\min \end{array}$ & $\begin{array}{l}\text { PACU + } \\
105 \text { min }\end{array}$ & $\begin{array}{l}\text { PACU + } \\
120 \text { min }\end{array}$ & $\begin{array}{l}\mathrm{PACU}+ \\
240 \mathrm{~min}\end{array}$ \\
\hline \multicolumn{11}{|c|}{ NRS value for pain at rest } \\
\hline $\begin{array}{l}\text { Remifentanil } \\
\text { group }\end{array}$ & $2.53 \pm 2.32$ & $2.60 \pm 2.19$ & $3.06 \pm 2.57$ & $2.86 \pm 1.99$ & $3.26 \pm 1.94$ & $2.73 \pm 1.71$ & $2.93 \pm 1.58$ & $2.66 \pm 1.54$ & $2.06 \pm 1.33$ & $1.86 \pm 1.72$ \\
\hline \multirow{2}{*}{$\begin{array}{l}\text { Control } \\
\text { group }\end{array}$} & $4.53 \pm 2.93$ & $5.23 \pm 2.86$ & $5.15 \pm 2.44$ & $4.46 \pm 2.22$ & $3.46 \pm 2.25$ & $2.46 \pm 1.94$ & $2.07 \pm 1.70$ & $1.84 \pm 1.34$ & $1.61 \pm 1.04$ & $1.30 \pm 1.25$ \\
\hline & $\begin{array}{l}P \text { value for } \\
P \text { value for } \\
P \text { value for }\end{array}$ & $\begin{array}{l}\text { difference bet } \\
\text { difference bet } \\
\text { nteraction: < }\end{array}$ & $\begin{array}{l}\text { ween groups } \\
\text { ween times: } \\
0.001\end{array}$ & $\begin{array}{l}0.358 \\
<0.001\end{array}$ & & & & & & \\
\hline \multicolumn{11}{|c|}{ NRS value for pain during head flexion } \\
\hline $\begin{array}{l}\text { Remifentanil } \\
\text { group }\end{array}$ & $2.80 \pm 2.33$ & $2.93 \pm 2.21$ & $3.40 \pm 2.66$ & $3.33 \pm 2.02$ & $3.80 \pm 1.93$ & $3.26 \pm 1.79$ & $3.46 \pm 1.50$ & $3.13 \pm 1.59$ & $2.66 \pm 1.75$ & $2.60 \pm 2.06$ \\
\hline \multirow{2}{*}{$\begin{array}{l}\text { Control } \\
\text { group }\end{array}$} & $5.00 \pm 3.13$ & $5.69 \pm 2.84$ & $5.30 \pm 2.84$ & $4.61 \pm 2.72$ & $4.00 \pm 2.76$ & $3.15 \pm 2.51$ & $2.76 \pm 2.42$ & $2.61 \pm 2.39$ & $2.38 \pm 2.32$ & $1.84 \pm 1.62$ \\
\hline & \multicolumn{10}{|c|}{$\begin{array}{l}P \text { value for difference between groups: } 0.418 \\
P \text { value for difference between times: }<0.001 \\
P \text { value for interaction: }<0.001\end{array}$} \\
\hline
\end{tabular}




\section{NRS Values for pain at rest}

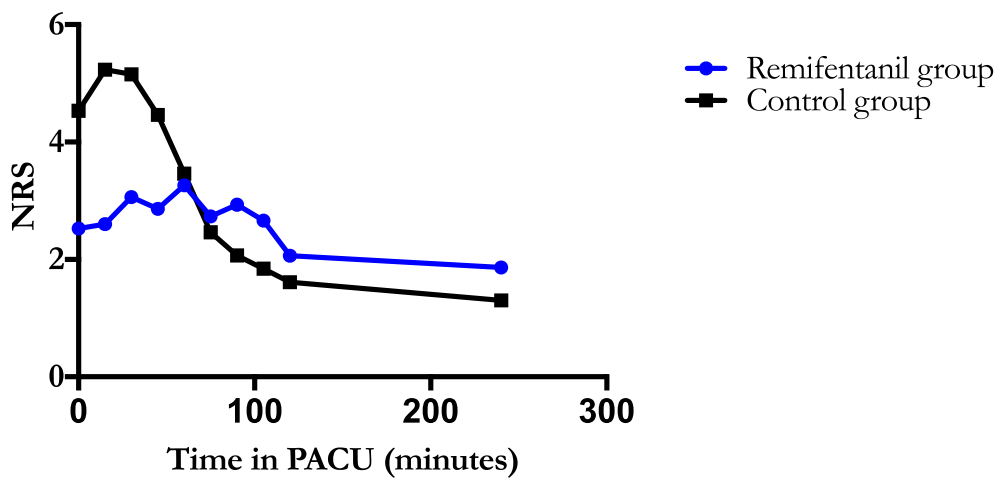

NRS Values during head flexion

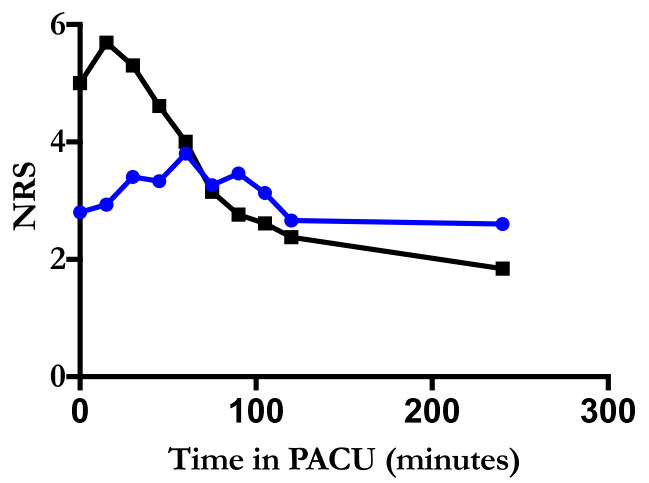

Fig. 2 a Illustrates the Numeric Rating Scale (NRS) values in both groups during their stay in the PACU while at rest. Pain evaluation was done upon arrival to the PACU and every 15 min during the first $2 \mathrm{~h}$ post-operatively, as well as after $4 \mathrm{~h}$. Patients evaluating their pain as $>3 / 10$ on the NRS received a morphine bolus ( $2 \mathrm{mg}$ every $5 \mathrm{~min}$ as needed). Values are Means \pm SD. 2 way-ANOVA for repeated measures. $P$ value for difference between both groups: $0.358 ; P$ value for difference between times: $<0.001 ; P$ value for interaction: $<0.001$. b Illustrates the Numeric Rating Scale (NRS) values in both groups during their stay in the PACU during a light head flexion. Upon arrival and every $15 \mathrm{~min}$ during the first $2 \mathrm{~h}$ post-operatively, as well as after $4 \mathrm{~h}$, patients were asked to do a light head flexion. During this moment, NRS values were recorded. Values are Means \pm SD. 2 way-ANOVA for repeated measures. $P$ value for difference between both groups: $0.418 ; P$ value for difference between times: $<0.001 ; P$ value for interaction: $<0.001$

showed a remarkably different trajectory (Fig. 2). The control group $(n=14)$ had declining NRS values starting relatively high, whereas the remifentanil group $(n=15)$ had zigzag values centered around 3/10. A likely explanation for this is that the remifentanil group still received an opioid, remifentanil, in addition to morphine, and was therefore less prone to experiencing pain. However, the remifentanil concentrations were quite low, especially in the second hour of the withdrawal phase, and consequently may not completely explain the observed differences in NRS values. Again, it could also be that our study was not powered adequately to fully examine NRS values.

Though the study demonstrated a delayed initial postoperative analgesic demand after a gradual withdrawal of

Table 4 Ramsay Sedation Scale score

\begin{tabular}{|c|c|c|c|c|c|c|c|c|c|c|}
\hline & $\begin{array}{l}\text { PACU } \\
\text { arrival }\end{array}$ & $\begin{array}{l}\text { PACU + } 15 \\
\min \end{array}$ & $\begin{array}{l}\text { PACU + } 30 \\
\min \end{array}$ & $\begin{array}{l}\mathrm{PACU}+45 \\
\min \end{array}$ & $\begin{array}{l}\text { PACU + } 60 \\
\min \end{array}$ & $\begin{array}{l}\mathrm{PACU}+75 \\
\min \end{array}$ & $\begin{array}{l}\text { PACU + } 90 \\
\min \end{array}$ & $\begin{array}{l}\text { PACU + } \\
105 \text { min }\end{array}$ & $\begin{array}{l}\mathrm{PACU}+ \\
120 \mathrm{~min}\end{array}$ & $\begin{array}{l}\mathrm{PACU}+ \\
240 \mathrm{~min}\end{array}$ \\
\hline $\begin{array}{l}\text { Remifentanil } \\
\text { group }\end{array}$ & $2.46 \pm 0.91$ & $2.46 \pm 0.64$ & $2.53 \pm 0.64$ & $2.53 \pm 0.64$ & $2.40 \pm 0.63$ & $2.33 \pm 0.61$ & $2.33 \pm 0.61$ & $2.47 \pm 0.74$ & $2.47 \pm 0.74$ & $2.06 \pm 0.25$ \\
\hline Control group & $\begin{array}{l}2.21 \pm 0.57 \\
P \text { value for } \\
P \text { value for } \\
P \text { value for }\end{array}$ & $\begin{array}{l}2.07 \pm 0.47 \\
\text { ifference bet } \\
\text { ifference bet } \\
\text { iteraction: } 0.0\end{array}$ & $\begin{array}{l}2.07 \pm 0.47 \\
\text { veen groups: } \\
\text { veen times: } 0 \\
47\end{array}$ & $\begin{array}{l}2.14 \pm 0.36 \\
0.337 \\
224\end{array}$ & $2.14 \pm 0.36$ & $2.37 \pm 0.63$ & $2.28 \pm 0.46$ & $2.42 \pm 0.75$ & $2.35 \pm 0.74$ & $2.21 \pm 0.57$ \\
\hline
\end{tabular}


remifentanil, another limitation was that it was conducted on patients who underwent relatively minor thyroid surgeries. Larger studies must be done in major surgeries in order to see whether the results from this study can be reproduced in patients who experience greater noxious stimuli and further our understanding of some of the NRS interactions revealed in our study.

\section{Conclusion}

Though overall morphine consumption, numeric rating scale scores, Ramsay Sedation Scale scores, and quality of recovery scores (QoR-40) are not altered, a gradual withdrawal of remifentanil after thyroid surgery is safe and associated with a delayed initial post-operative demand of analgesic drugs. The withdrawal process does, however, require vigilance and training.

\section{Abbrevations}

LTP: Long term potentiation; NMDA: N-methyl-D-aspartate; NRS: Numeric Rating Scale; PACU: Post-anesthesia care unit; QoR: quality of recovery; TCl: Target controlled infusion

\section{Acknowledgements}

The authors thank the nursing staff of the Erasme hospital, Brussels. Data from this study were presented at the IARS annual conference (Chicago 2018).

\section{Funding}

This study was entirely supported by departmental funding.

\section{Availability of data and materials}

In order to protect patient privacy and identity, data analysed during the current study are available on reasonable request.

\section{Authors' contributions}

All authors have read and approved the manuscript. SS: patient recruitment, data collection, writing up draft of the paper. KG: patient recruitment, data collection. WT: study material preparation, study design. $\mathrm{IH}$ : patient recruitment, data collection. DN: revision of draft of the paper. MC: patient recruitment, data collection. LB: study design, supervision. EE: data analysis and interpretation, supervision.

\section{Ethics approval and consent to participate}

This study was approved by the internal review board (03/30/2017; P2017/ 074; Comité Ethique, Erasme hospital, Brussels; Chairman: Jean-Marie Boeymans). The trial was registered on clinicaltrials.gov (NCT03110653; PI: Luc Barvais; date of registration: 03/31/2017).

Written informed consent was obtained from each patient participating in the study.

\section{Consent for publication}

Written informed consent was obtained from each patient participating in the study.

\section{Competing interests}

The authors declare that they have no competing interests. As of October 2017, SS is a recipient of a research fellowship of the Belgian American Education Foundation.

\section{Publisher's Note}

Springer Nature remains neutral with regard to jurisdictional claims in published maps and institutional affiliations.

\section{Author details}

'Department of Anesthesia and Perioperative Care, CUB Erasme University Hospital, Université Libre de Bruxelles, 808, Route de Lennik, 1070 Brussels,
Belgium. ${ }^{2}$ Department of Anesthesia and Perioperative Care, Zuckerberg San Francisco General Hospital \& Trauma Center, University of California, San Francisco, USA. ${ }^{3}$ Department of Anesthesiology, H. Lee Moffitt Cancer Center \& Research Institute, University of South Florida, Tampa, USA. ${ }^{4}$ Department of Cardiothoracic Surgery, CUB Erasme University Hospital, Université Libre de Bruxelles, Brussels, Belgium.

Received: 17 December 2018 Accepted: 5 April 2019

Published online: 25 April 2019

\section{References}

1. Fletcher D, Martinez V. Opioid induced hyperalgesia in patients after surgery: a systematic review and a meta-analysis. $\mathrm{Br} J$ Anaesth. 2014;112: 991-1004.

2. Guignard B, Bossard AE, Coste C, et al. Acute opioid tolerance: intraoperative remifentanil increases postoperative pain and morphine requirement. Anesthesiology. 2000;93:409-17.

3. Yu EHY, Tran HD, Lam SW, Irwin MG. Remifentanil tolerance and hyperalgesia: short-term gain, long term pain? Anaesthesia. 2016;71:1347-62.

4. Albrecht S, Fechner J, Geisslinger G, et al. Postoperative pain control following remifentanil-based anaesthesia for major abdominal surgery. Anaesthesia. 2000:55:315-22.

5. Didla R, Gassner M, Gingl E, Sandkuhler J. Induction of synaptic long-term potentiation after opioid withdrawal. Science. 2009:325:207-10.

6. Comelon M, Raeder J, Stubhaug A, Nielsen CS, Draegni T, Lenz H. Gradual withdrawal of remifentanil infusion may prevent opioid induced hyperalgesia. Br J Anaesth. 2016;116:524-30.

7. Sprenger C, Eichler IC, Eichler L, Zollner C, Buchel C. Altered signaling in the descending pain modulatory system after short-term infusion of the $\mathrm{mu}$ opioid agonist remifentanil. J Neurosci. 2018;38:2454-70.

8. Myles PS, Weitkamp B, Jones K, Melick J, Hensen S. Validity and reliability of a postoperative quality of recovery score: the QoR- $40 . \mathrm{Br} J$ Anaesth. 2000;84:11-5.

9. Ramsay MA, Savege TM, Simpson BR, Goodwin R. Controlled sedation with alphaxolone-al phadalone. BMJ. 1974;2:656-9.

10. Sandkühler J, Gruber-Schoffnegger D. Hyperalgesia by synaptic long-term potentiation (LTP): an update. Curr Opin Pharmacol. 2012;12:18-27.

11. Richebé $P$, Cahana A, Rivat C. Tolerance and opioid-induced hyperalgesia. Is a divorce imminent. Pain. 2012:153:1547-8.

12. Lee M, Silverman SM, Hansen H, Patel VB, Manchikanti L. A comprehensive review of opioid-induced hyperalgesia. Pain Physician. 2011;14:145-61.

13. Richebé $\mathrm{P}$, Pouquet $\mathrm{O}$, Jelacic $\mathrm{S}$, et al. Target-controlled dosing of remifentanil during cardiac surgery reduces postoperative hyperalgesia. J Cardiothorac Vasc Anesth. 2011:25:917-25.

Ready to submit your research? Choose BMC and benefit from

- fast, convenient online submission

- thorough peer review by experienced researchers in your field

- rapid publication on acceptance

- support for research data, including large and complex data types

- gold Open Access which fosters wider collaboration and increased citations

- maximum visibility for your research: over 100M website views per year

At BMC, research is always in progress.

Learn more biomedcentral.com/submissions 